\title{
Perceived Hearing Handicap and Social Isolation Among Elderly with Hearing Impairment Attending Zagazig University Hospitals
}

\author{
Eman Shokry Abd Allah*, Noha Gamal El-Sayed and Fatma Mohammed Ahmed \\ Zagazig University, Egypt
}

*Corresponding author: Eman Shokry Abd Allah, Professor of Gerontological Nursing, Faculty of Nursing, Zagazig University, Egypt.

Received Date: December 18, 2018

Published Date: January 07, 2019

\begin{abstract}
The ability to interact with others, and perceive dangers depends momentously on the capacity to hear. Lack of social networking has detrimental influences on older adults' health in a complex dynamic manner. Hereafter, the current study aimed to assess self-perceived hearing handicap and social isolation among the elderly with hearing impairment. Subsequently, a cross-sectional descriptive research design was opted, where the study enrolled a purposive sample of 130 elderly attending the auditory unit at Zagazig University Hospitals, Egypt. The data collected pertained to demographic and hearing characteristics, Lubben Social Network Scale-revised [LSNS-R], and Hearing Handicap Inventory Elderly-Screening version [HHIE-S]. Data analysis results revealed that $80.8 \%$ reported low self- perceived hearing handicap and $77.7 \%$ experienced low social networking. Taken as a whole, LSNS-R and HHIE-S were significantly related to hearing impairment level. Henceforth, early picking up of socially isolated elderly and developing effective interventions to reduce it is of the utmost importance.
\end{abstract}

Keywords: Perceived; Hearing handicap; Social isolation; Elderly; Hearing impairment; Zagazig university hospitals

\section{Introduction}

Hearing impairment (HI) afflicted a noteworthy and growing percentage of the adult population. Overall hearing impairment and disabling Hearing Impairment affects Egyptian people by prevalence rates of $16.0 \% \& 2.9 \%$ respectively according to National household survey in randomly selected governorates in Egypt [1]. The prevalence is expected to increase with an aging population. Where the number of old people reached 946.469 million in 2018 $(6.7 \%)$ of the total Egyptian population [2].

Hearing impairment alludes to any limitation or lack of ability to understand sound and to execute tasks because of hearing difficulties experienced by individuals with hyperacusis. Whilst, hearing handicap refers to the emotional and social aspects resulting from hearing impairment, which can sometimes restrict the individual's participation in everyday activities, as well as impact family relationships and social interactions [3]. Social networks tend to shrink in older age because of numerous life transitions such as retirement, relocation to supportive housing, and the loss of friends and partners through death. When physical and mental capacities decline, older people may find it more difficult to maintain their relationship or build new ones. These experiences can increase the risk of loneliness (dissatisfaction with the quantity and quality of social relations) and of social isolation (lack of social contact). Estimates of the prevalence of social isolation, among older people, range from 7 to $17 \%$, while about $40 \%$ of older people report feeling lonely [4].

Although the typical human ear can perceive sounds at frequencies from 20 to $20,000 \mathrm{~Hz}$, the foremost critical range for speech processing is 4 to $5 \mathrm{KHz}$ [5]. There is frequently discordance between objectively measured deficits in tonal perception at particular frequencies and intensity levels (measured as decibels) and subjective perceptions of hearing difficulties. Hearing problems in spite of normal hearing tests might be caused by abnormal signal processing or sound discernment. As a result of hearing loss, treatment is focused on improving tonal perception by the signal amplification the term "hearing impairment" is employed to refer precisely to deficits found on pure-tone audiogram which considered the standard objective test for hearing loss [6]. 
Presbycusis is the most common cause of poor hearing. Communication errors induced from Presbycusis strain interpersonal relationships and contribute to depression and social isolation [7]. Some research suggests that social isolation may become more prevalent with increasing age. In fact, 7.9\%of older adults report some social isolation, with $4.8 \%$ being isolated or very isolated [8]. Hearing impairment affects all aspects of life that depend on the ability to communicate with other people. Furthermore, the symptoms related to the severe to profound hearing impairment such as tinnitus and vertigo were found to have a negative impact on quality of life [9]. Effective communication is crucial to active aging and well-being however, virtually all older adults notice it challenging to communicate successfully in noisy situations. The ensuing distress and frustration can provoke withdrawal or avoidance of social circumstances, which, in turn, can seriously restrain the extent of activities accessible to older adults and cause a less dynamic and fulfilling way of life, and, in a few cases, depression [10].

Gerontological nurse actions are based on assessment findings and may embody referral to an audiologist after sharing resources for hearing impairment, education on hearing impairment (including prevention and consequences), hearing aids, assistive devices, and communication techniques. Nurses can play an essential role in providing older adults with the information they need to improve their hearing and dodge the negative consequences of untreated hearing impairment [11].

\section{Subjects and Methods}

\section{Research design}

A Cross-sectional descriptive design was opted to investigate the perceived hearing handicap and social isolation among the elderly with hearing impairment attending Zagazig University Hospitals, Egypt. The permissions were obtained when reviewing the tools used.

\section{Study setting}

The existing study was conducted at the auditory unit at Zagazig University Hospitals, Egypt.

\section{Subjects}

A purposive sample of 130 non-demented hearing-impaired older adults aged 60 years and more were enrolled in the study. Sample size calculation: The sample size was determined to be 130 by applying for the "Open Epi software package" program, at confidence interval $95 \%$ and power $80 \%$.

\section{Tools of Data Collection}

Three tools were used for collecting data of the present study, they were:

\section{Tool I: Demographic and hearing characteristics}

The interview questionnaires included three parts; sociodemographic data of the subjects such as sex, education level, age, marital status, and previous occupation...etc., and history of chronic diseases. The Hearing condition was attained from the elderly record and determined by a question asking which the affected ear, duration of hearing impairment, the use of hearing aid, and its duration. Moreover, the standard objective test for obtaining thee degree and pattern of hearing impairment over frequencies is the pure-tone audiogram, in which participants were tested individually in a soundproof booth and tested on ability to hear tones at a sequence of discrete frequencies, typically within the range of 125 to $8000 \mathrm{~Hz}$, at different decibels. This procedure was executed through a clinical calibrated audiometer (Orbiter 922 Version 2) with supra-aural earphones. A microphone (in the sound booth steered into the audiometry equipment) transferred the reactions of participants through an earphone connected to the audiometry apparatus. The participant's verbal reaction was recorded. For Analysis; the thresholds were measured in decibels hearing level (dB HL). Pure-tone averages (PTAs) were calculated to measure hearing acuity as the mean of pure tone thresholds at "0.5", " 1 ", "2", and " 4 " kHz. PTA was categorized in accordance with the following established cutoffs for grading of hearing impairment classification "mild: $25 \leq 40 \mathrm{~dB}$ HL, moderate: $40 \leq 70 \mathrm{~dB} \mathrm{HL}$, and severe: $>70 \mathrm{~dB}$ HL".

\section{Tool II: Hearing handicap inventory elderly-screening version [HHIE-S]}

This auditory screening tool was designed to measure the perceived psychosocial effects of hearing impairment on specific areas of a person's life. The instrument composed of 10 items; five cover emotional aspects and the other five social and situational aspects. Items were scored " 2 ", " 1 ", and " 0 " for the responses "yes", "sometimes", and "no" respectively. The total of each category and for the total scale was summed up and converted into a percent score, which classified as follows: High perception of auditory handicaps $(\geq 60 \%)$ and Low perception of auditory handicaps $(<60 \%)$ [12].

\section{Tool III: Lubben social network scale-REVISED [LSNS-R]}

It was designed to measure social isolation in older adults by gauging perceived support received by family \& friends, including confidant relationships and assessing size, closeness, and frequency of contacts of a participant's social network. This tool consists of an equally weighted sum of 12 items, which comprised Family and Friendships domain. The items were scored from zero to five for the responses from "none" to "9 or more" respectively. The total of each category and for the total scale was converted into a percent score, which was classified as follows: high social networking ( $\geq 60$ $\%)$ and low social networking (<60\%) [13].

\section{Validity}

The tools' validity was done by a group of the panel who were three specialists from nursing and medical faculty staff who revised the tools and ascertained its clarity, significance, and comprehensiveness.

\section{Reliability}

Reliability of scales was tested by using Cronbach's alpha test in SPSS V.20 as the following: Cronbach's alpha values were 0.849 for HHIE-S and 0.838 for LSNS-R. 


\section{Statistical Design}

Data entry and statistical analysis were done using SPSS 20.0 statistical software package. Data were presented using descriptive statistics in the form of frequencies and percentages for qualitative variables and means and standard deviations and medians for quantitative variables. Cronbach alpha coefficient was calculated to assess the reliability of the scales through their internal consistency. Spearman rank correlation was used for assessment of the inter-relationships among quantitative variables and ranked ones. Multiple linear regression analysis was used and analysis of variance for the full regression models done. Statistical significance was considered at $\mathrm{p}$-value $<0.05$.

\section{Result}

Regarding socio-demographic characteristics and medical history of elderly in the study sample, it was found that $72.3 \%$ of elderly aged 60 to less than 70 years, $62.3 \%$ were males and $58.2 \%$ were married. Considering the educational level, $78.2 \%$ of them had no formal education. Referring to the previous job, $46.2 \%$ were workers previously. Additionally, $73.8 \%$ of elderly belonged to rural areas, and $80.8 \%$ lived with their families, where crowding index was less than 2/room (83.8\%). Regarding income, 39.2\% and $77.7 \%$ had insufficient monthly income and pension was the source of their income respectively. Concerning the medical history of elderly, poor health condition was highlighted, where $53.8 \%$ of elderly had chronic diseases, where the highly reported diseases were hypertension, diabetes, and arthritis (25.4\%, 19.2\% \&17.7\%) respectively.

Table 1: History of the hearing problem among elderly in the study sample $(\mathrm{N}=130)$.

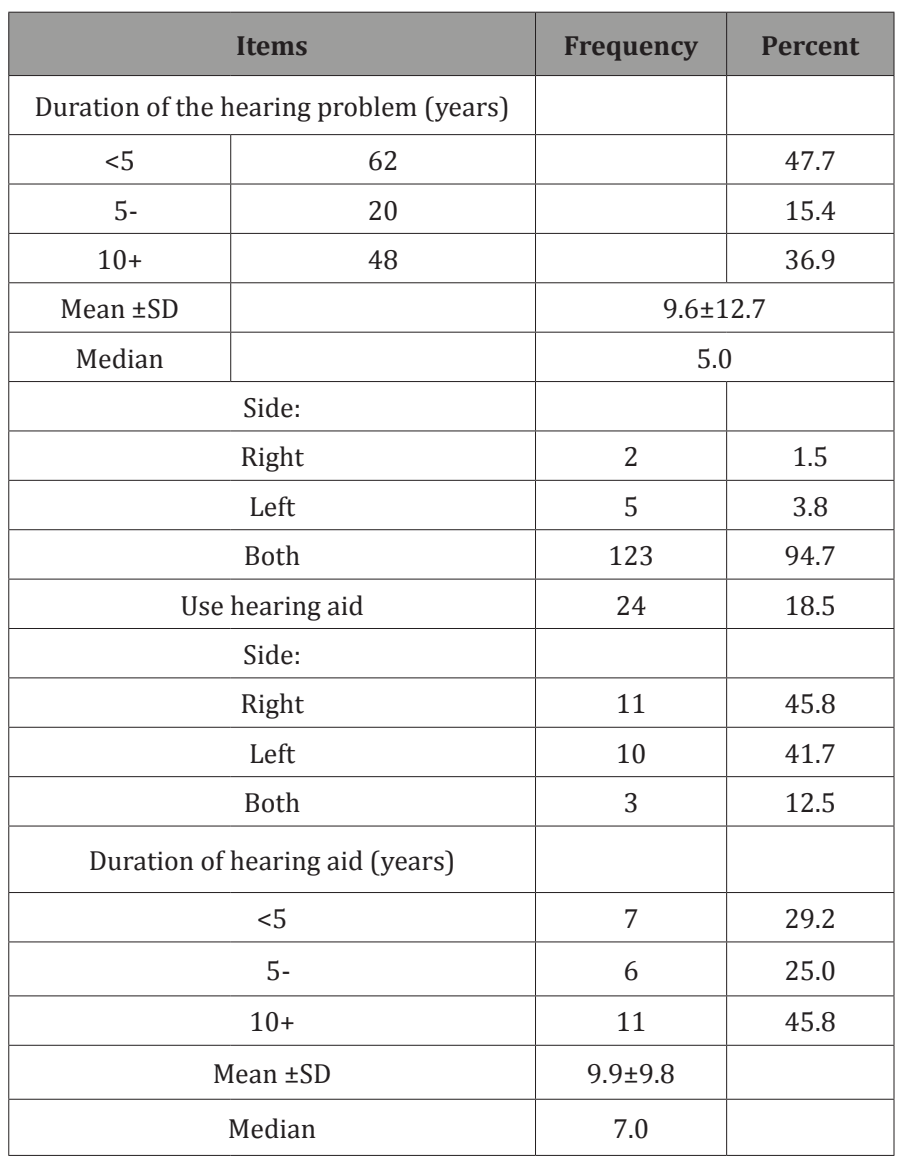

Referring to the history of the hearing problem among elderly (Table 1), it was found that $47.7 \%$ had hearing impairment since less than 5 years and $94.6 \%$ suffered from bilateral hearing impairment. As regards, hearing aids' usage and its duration, 18.5\% of elderly used hearing aids whether unilaterally or bilaterally, whereas, the higher duration was for 10 years or more (45.8\%).

Figure 1 stratifies degrees of hearing impairment among the elderly in the study sample. As the figure displays, the most commonly reported degree of hearing impairment among elderly was the moderate degree in the right, left, and both ears $(40.8 \%$, $41.5 \%$, and $48.5 \%$ ) respectively.

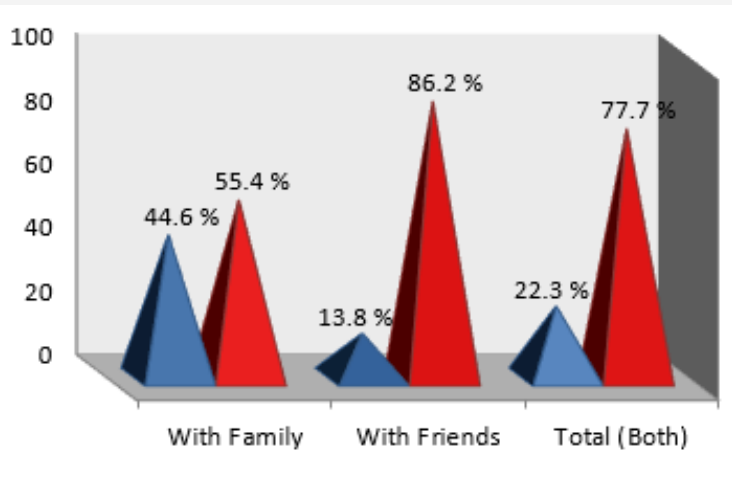

- High Social Networking(+60\%) — Low Social Networking

Figure 1: Social networking among elderly with hearing impairment $(\mathrm{N}=130)$.

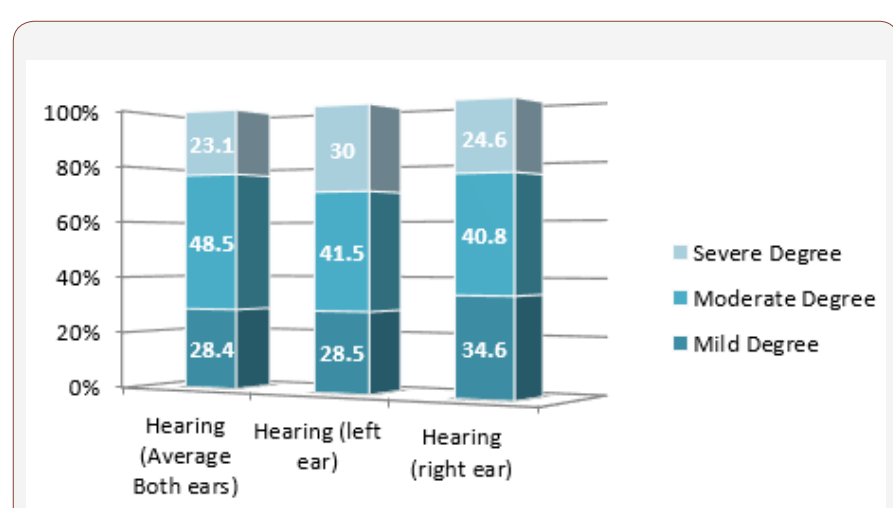

Figure 2: Degrees of hearing impairment among elderly in the study sample $(\mathrm{N}=130)$.

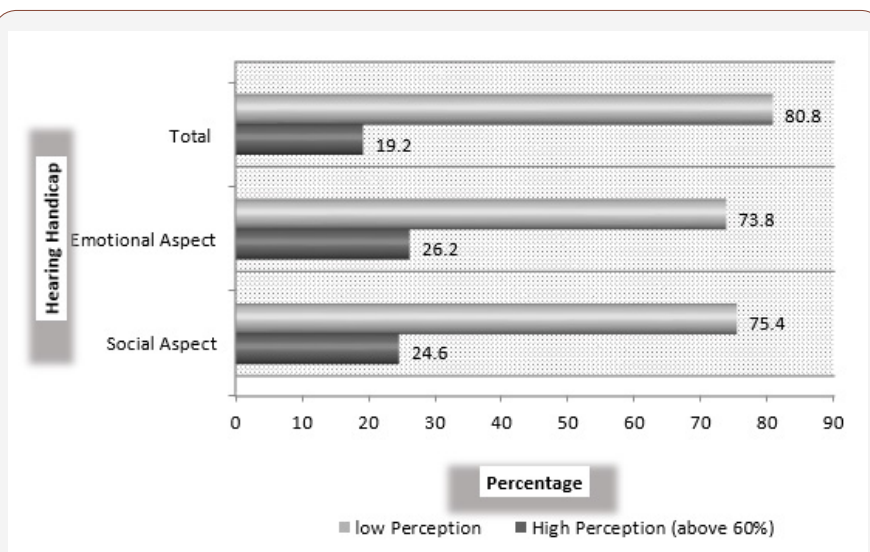

Figure 3: Elderly perception of hearing handicap in the study sample $(\mathrm{N}=130)$. 
As to social isolation among studied older adults, Figure 2 depicts that $86.2 \%$ of elderly in the study sample were socially isolated from friends, and $77.7 \%$ were socially isolated from both friends and families. Figure 3 illustrates that higher percentage of elderly had a low perception of hearing handicap at social and emotional aspect $(75.4 \%$ \& $73.8 \%)$ respectively, as well as the total self-perception of hearing handicap among elderly was low (80.8\%).

Table 2: Correlation matrix of elderly scores of perception of hearing handicap, and Lubben social networking and their hearing levels. [(*) Statistically significant at $\left.p<0.05 ;{ }^{* *}\right)$ Statistically significant at $\left.p<0.01\right]$.

\begin{tabular}{|c|c|c|c|c|c|c|}
\hline Hearing Levels (dB) & \multicolumn{5}{|c|}{ Spearman's Rank Correlation Coefficient } \\
\hline & Social Effect & Emotional Effect & Total Perception & Lubben Family & Lubben Friends & Lubben Total \\
\hline Right ear & $.620^{* *}$ & $.448^{* *}$ & $.589^{* *}$ & -.148 & -.147 & -.167 \\
\hline Left ear & $.498^{* *}$ & $.414^{* *}$ & $.523^{* *}$ & -.165 & -.146 & -.168 \\
\hline Both ears (average) & $.607^{* *}$ & $.465^{* *}$ & $.602^{* *}$ & -.170 & -.171 & $-.188^{*}$ \\
\hline Duration of hearing problem & -.005 & $.355^{* *}$ & $.358^{* *}$ & $.416^{* *}$ & -.089 & -.079 \\
\hline
\end{tabular}

Table 2 expounds a statistically significant positive correlation between total perception of hearing handicap \& bilateral hearing impairment, and duration of the hearing problem $(\mathrm{p}<0.01)$. Moreover, a statistically significant negative correlation was found between total social networking and both ears average hearing impairment $(\mathrm{p}<0.05)$.

Table 3: Correlation matrix of elderly scores of perception of hearing handicap, and Lubben social networking. $\left[\left(^{*}\right)\right.$ Statistically significant at $p<0.05$; $\left({ }^{* *}\right)$ Statistically significant at $\left.p<0.01\right]$.

\begin{tabular}{|c|c|c|c|c|c|c|}
\hline Elderly & \multicolumn{5}{|c|}{ Spearman's Rank Correlation Coefficient } \\
\hline Social effect & & Emotional Effect & Total Perception & Lubben Family & Lubben Friends & Lubben Total \\
\hline Emotional effect & $.541^{* *}$ & & & & & \\
\hline Total effect & $.839^{* *}$ & $.904^{* *}$ & & & & \\
\hline Lubben (family) & $-.187^{*}$ & $-.259^{* *}$ & $-.259^{* *}$ & & & \\
\hline Lubben (friends) & $-.271^{* *}$ & -.158 & $-.239^{* *}$ & $.477^{* *}$ & & \\
\hline Total Lubben & $-.276^{* *}$ & $-.227^{* *}$ & $-.283^{* *}$ & $.814^{* *}$ & $.886^{* *}$ & \\
\hline
\end{tabular}

Table 4: Correlation matrix of elderly scores of perceptions of the hearing handicap, and Lubben social networking and their personal characteristics. $\left[\left(^{*}\right)\right.$ Statistically significant at $p<0.05 ;(* *)$ Statistically significant at $\left.\left.p<0.01\right].\right]$.

\begin{tabular}{|c|c|c|c|c|c|c|}
\hline \multirow[t]{2}{*}{ Characteristics } & \multicolumn{6}{|c|}{ Spearman's Rank Correlation Coefficient } \\
\hline & Social Effect & Emotional Effect & Total Perception & Lubben Family & Lubben Friends & Lubben Total \\
\hline Age & .112 & .011 & .061 & -.036 & .008 & -.002 \\
\hline Education & $.230^{* *}$ & -.131 & $-.197^{*}$ & $.253^{* *}$ & $.337^{* *}$ & $.352^{* *}$ \\
\hline Crowding index & $.221^{*}$ & .127 & $.177^{*}$ & .160 & .056 & .119 \\
\hline Income & $-.204^{*}$ & -.119 & $-.177^{*}$ & $.253^{* *}$ & $.250^{* *}$ & $.296^{* *}$ \\
\hline No. of chronic diseases & -.072 & .057 & -.003 & -.085 & -.093 & -.111 \\
\hline
\end{tabular}

Table 5: Best fitting multiple linear regression model for the perception of hearing handicap score. [r square=0.44; Model ANOVA: $F=24.52, p<0.001$; Variables entered and excluded: age, gender, marital status, residence, live with family, duration of hearing problem].

\begin{tabular}{|c|c|c|c|c|c|c|c|}
\hline \multirow{2}{*}{ Elderly } & \multicolumn{2}{|c|}{ Unstandardized Coefficients } & \multirow{2}{*}{$\begin{array}{c}\text { Standardized } \\
\text { Coefficients }\end{array}$} & \multirow{2}{*}{ t-test } & \multirow{2}{*}{ p-value } & \multicolumn{2}{|c|}{$\begin{array}{c}95 \% \text { Confidence Interval } \\
\text { for B }\end{array}$} \\
\hline & B & Std. Error & & & & Lower & Upper \\
\hline Constant & 8.24 & 5.93 & & 1.390 & 0.167 & -3.49 & 19.97 \\
\hline Income & -5.97 & 2.26 & -0.18 & -2.642 & 0.009 & -10.45 & -1.50 \\
\hline Chronic disease & 8.24 & 3.37 & 0.17 & 2.449 & 0.016 & 1.58 & 14.90 \\
\hline Use hearing aid & 14.95 & 5.07 & 0.24 & 2.948 & 0.004 & 4.91 & 24.98 \\
\hline Hearing impairment level (average) & 0.56 & 0.09 & 0.49 & 6.001 & $<0.001$ & 0.38 & 0.75 \\
\hline
\end{tabular}

Referring to multivariate analysis of HHIE-S score, Table 5 indicates that the average hearing impairment degree was a statistically significant independent positive predictor of elderly perception of hearing handicap score. Precisely, the average degree
Table 3 clarifies that the lower the perception of hearing handicap, the higher the elderly social networks $(p<0.01)$. According to Table 4, the results point to a statistically significant negative correlation between total elderly perception of hearing handicap and their education and income $(\mathrm{p}<0.05)$. Meanwhile, a statistically significant positive correlation was found between total social networking and their education and income $(\mathrm{p}<0.01)$. 


\section{Discussion}

Remarkably, the most prevalent degree of hearing impairment in the current study was moderate degree followed by mild and severe, this finding was similar to Olaosun et al. [14] in Nigeria. Such a result might be ascribed to that, in most cases, hearing impairment happens slowly over time and may be accepted as a natural occurrence accompanied by the aging process. Paradoxically, Genther et al. [15] conducted survey in the U.S.A and concluded that the degree of hearing loss was commonly in mild degree (more than half) followed by moderate then severe (less than one-tenth). This difference in results might be due to the fact that older adults in western countries are accustomed to doing periodic body checkup, including audiological testing, so that hearing impairment is detected and managed in an early stage.

Regarding the degree of elderly perception of hearing handicap, the current study explicated that most of hearing-impaired elderly had a low perception of hearing handicap at social and emotional aspect. Possible reasons for such result are; Family structure and familial norms in the Egyptian society, where co-residence with children, family care and inter-generational (extended family) living are traditionally more common and more expected in Egypt. Sons marry and live with them in the same house or neighborhood especially in rural areas, so the elderly can receive support from them. Further, the younger generation may adapt communication strategies to help the elderly to understand conversations especially in the mild and moderate degree of hearing impairment and consequently the perception of being handicapped reduced. Another plausible rationale might be that the hearing-impaired older adults may have normal hearing in low frequency, while they had a loss in the mild and high frequencies ( $>2 \mathrm{kHz}$ ). Thus, speech is audible but takes on a muffled character and is difficult to understand, especially in the presence of noisy background. As this type of hearing loss usually develops gradually over many years, the individual may be unaware of the impairment and the perception of handicapping, because of the ability to respond to low-frequency sounds in speech.

Regarding the range of elderly social networking, the present study clarified that most of the elderly experienced social isolation in terms of small social networks particularly friends. Possible explanations of such result are; First, elderly people go through life course changes, such as retirement and bereavement which may lead to a loss of social roles and poor health conditions such as mobility impairments which may limit participation in social activities and gradual withdrawal from participation in society especially with friends outside the home. Second, the shift to quieter environments is related more to lifestyle preferences that naturally change with age. Lastly, the transportation barrier can restrict access to opportunities such as developing and maintaining a close network of friends and relatives, access to health facilities, shops, and amenities. This finding is conflicting with previous studies as Hand et al. [16] in Denver, USA, who concluded that almost onequarter of the sample was socially isolated in terms of the size of their close social network. A greater proportion (one third) of participants scored as isolated on the friends' subscale than on the family subscale (almost one fifth). Also, Shimada et al. [17] in the
Tohoku region, Japan reported that the overall prevalence of social isolation was $25.7 \%$ among the elderly. As well, Chatters et al. [18] who carried out a study in Michigan, USA and indicated that most of older adults in the sample were not objectively isolated from their extended family or friends. In the same context, the results of an Italian study conducted by Quaranta et al. [19] showed that self-perceived hearing handicap was low in the study sample; one-quarter of the population reported a hearing handicap. As well, Chang et al. [20] who carried out a cross-sectional survey of individuals aged 65 years and older and concluded that about one-fifth of subjects with hearing impairment reported a hearing handicap. On the contrary, a study conducted by Servidoni \& Conterno, [3] in the city of Marília, Brazil revealed that among 110 subjects with abnormal audiometry, most of them showed some degree of perceived handicap. The variations in culture, health services, and attitudes highlight how the experience of aging and its related health problems can vary according to where one lives.

Considering the utilization of hearing aids among the elderly in the study sample, the results highlighted the dearth of using hearing aids by the elderly (nearly one fifth). This result might be due to the cost barriers or social stigma. Where no devices are formally given at the country expense to all unable people particularly whose age 60 years or over. Also, people with hearing aids are perceived and viewed by others to be old, disabled, less interesting, and less intelligent than people without it. This result is in harmony with a study carried out in the USA by Chien \& Lin [21] who confirmed that lower the percentage of older adults with hearing loss actually use custom-fit amplification.

The current study explicated that hearing impairment degree was a statistically significant independent positive predictor of perception of hearing handicap score. Such result might be attributed to the communication difficulties associated with the greater degree of HI which may lead to self-perception of frustration, embarrassment, consequently withdrawal from social occasions and in turn poorer life satisfaction and the higher degree of selfperceived hearing handicap. In the same vein, Gopinath et al. [22] in Sydney, Australia concluded that measured hearing impairment was an independent predictor of self-perceived hearing handicap. Around two out of three older adults with measured hearing impairment went on to develop self-perceived hearing handicap within 5 years.

Based on the current study findings, a statistically significant negative correlation was found between total social networking and hearing impairment degree. Possible explanations of such result are; HI might be associated with co-morbidity, poor mobility, dependence, lower health status, and cognitive decline, all of which can contribute to social isolation. Additionally, hearingimpaired older adults may feel shame and socially embarrassed due to difficulties in understanding what is being said and giving inappropriate responses to questions or statements. Inability to understand verbal communication results in feelings of isolation when elders are left out of group conversations. To avoid shame, elders with hearing loss sometimes choose isolation. As a consequence, social gatherings may become difficult. In the same context, Mick et al. [23] in the USA concluded that the greater 
hearing loss was associated with increased odds of social isolation in female older adults.

Regarding the relation between the elderly perception of hearing impairment and social networking, a statistically significant negative correlation was clarified between elderly perception of hearing handicap and their social networking. A possible explanation for such result is; when the elderly perceived a hearing deficit socially or emotionally in everyday life, it became a precursor to feeling disabled by hearing loss, depressive symptoms, and frustration, as reported in the study sample and in turn limits their participation in society and their isolation from others. In the same context, Weinstein \& Ventry [24] in the USA found that people who were socially isolated had a greater self-perceived hearing disability.

\section{Conclusion}

The data from this research support the conclusion that hearing impairment among aged people predominated by male sex, having no formal education, rural residence, and co-morbidity (highlighted by hypertension, diabetes, and arthritis). Bilateral hearing impairment was marked for the duration of more than five years, mainly started before the age of 60 years. The focal points of study findings are that not all elderly people with impaired hearing function perceived a hearing deficit socially or emotionally in everyday life (hearing handicap), and the social networking, especially with friends, also have been deteriorated. It is well noticed that the higher the level of HI, the lower educational level, and lower income of elderly plays an eloquent role in worsening elderly self-perceived hearing handicap, and social isolation mainly with family than friends.

\section{Recommendations}

The current study findings revealed that the highly reported hearing impairment was an advanced degree, so there is large need to implement screening programs for early identification and management of ear diseases at an earlier time especially in rural areas to reduce deterioration. It is also imperative to empower hearing-impaired older adults with sound communication techniques approaches to reduce the prevalence of social isolation.

\section{Conflict of Interest}

No conflict of interest.

\section{References}

1. Abdel Hamid O, Khatib O, Aly A, Morad M, Kamel S (2007) Prevalence and patterns of hearing impairment in Egypt: a national household survey. Eastern Mediterranean Health Journal.13(5): 1170-1180.

2. CAPMAS (2018) Population Estimates By Sex, Age Group \& Total Egypt population census; Egypt in Figures, Table No (3).

3. Servidoni AB, Conterno Ld O (2018) Hearing Loss in the Elderly: Is the Hearing Handicap Inventory for the Elderly-Screening Version Effective in Diagnosis When Compared to the Audiometric Test? International archives of otorhinolaryngology 22(1): 1-8.

4. Michel JP, Beattie BL, Martin FC, Walston JD (2018) Oxford Textbook of Geriatric Medicine. Oxford University Press, UK.
5. Schnupp J, Nelken I, King A (2011) Auditory neuroscience: Making sense of sound. MIT press.

6. Moyer VA (2012) Screening for hearing loss in older adults: US Preventive Services Task Force recommendation statement. Annals of internal medicine 157(9): 655-661.

7. Gates BJ, Walker KM (2014) Physiological changes in older adults and their effect on diabetes treatment. Diabetes Spectrum 27(1): 20-28.

8. Di Napoli EA, Wu B, Scogin F (2014) Social isolation and cognitive function in Appalachian older adults. Research on Aging 36(2): 161-179.

9. Carlsson PI, Hjaldahl J, Magnuson A (2015) Severe to profound hearing impairment: quality of life, psychosocial consequences and audiological rehabilitation. Disability and rehabilitation 37(20): 1849-1856.

10. Heinrich A, Gagne JP, Viljanen A, Levy DA, Ben-David BM, et al. (2016) Effective communication as a fundamental aspect of active aging and well-being: paying attention to the challenges older adults face in noisy environments. Social Inquiry into Well-Being 2(1).

11. Touhy TA, Jett KF (2015) Ebersole \& Hess' Toward Healthy Aging E-Book: Human Needs and Nursing Response, (9th Edn), Elsevier Health Sciences.

12. Ventry I, Weinstein B (1983) Identification of elderly people with hearing problems. Asha 25(7):37-42.

13. Lubben JE (1988) Assessing social networks among elderly populations. Family \& Community Health: The Journal of Health Promotion \& Maintenance 11(3): 42-52.

14. Olaosun AO, Ogundiran O, Tobih JE (2013) Hearing Loss among Elderly Patients in an Ear Clinic in Nigeria. Advances in Life Science and Technology 14: 81-86.

15. Genther DJ, Frick KD, Chen D, Betz J, Lin FR (2013) Association of hearing loss with hospitalization and burden of disease in older adults. Jama 309(22).

16. Hand C, Retrum J, Ware G, Iwasaki P, Moaalii G, et al. (2017) Understanding social isolation among urban aging adults: informing occupation-based approaches. OTJR: occupation, participation and health 37(4): 188-198.

17. Shimada K, Yamazaki S, Nakano K, Ngoma AM, Takahashi R et al. (2014) Prevalence of social isolation in community-dwelling elderly by differences in household composition and related factors: from a social network perspective in urban Japan. Journal of aging and health 26(5):807-823.

18. Chatters L, Taylor H, Nicklett E, Taylor R (2018) Correlates of Objective Social Isolation from Family and Friends among Older Adults. Healthcare $6(1): 24$.

19. Quaranta N, Coppola F, Casulli M (2014) The prevalence of peripheral and central hearing impairment and its relation to cognition in older adults. Audiology and Neurotology 19 (Suppl 1): 10-14.

20. Chang HP, Ho CY, Chou P (2009) The factors associated with a selfperceived hearing handicap in elderly people with hearing impairmentresults from a community-based study. Ear Hear 30(5): 576-583.

21. Chien W, Lin FR (2012) Prevalence of hearing aid use among older adults in the United States. Archives of internal medicine 172(3): 292-293.

22. Gopinath B, Hickson L, Schneider J (2012) Hearing-impaired adults are at increased risk of experiencing emotional distress and social engagement restrictions five years later. Age and Ageing 41(5): 618-623.

23. Mick P, Kawachi I, Lin FR (2014) The association between hearing loss and social isolation in older adults. Otolaryngology-Head and Neck Surgery 150(3): 378-384.

24. Weinstein BE, Ventry IM (1982) Hearing impairment and social isolation in the elderly. Journal of Speech, Language, and Hearing Research 25(4): 593-599. 